\title{
Pubertal Development in The Netherlands 1965-1997
}

\author{
DICK MUL, A. MIRANDA FREDRIKS, STEF van BUUREN, WILMA OOSTDIJK, \\ S. PAULINE VERLOOVE-VANHORICK, AND JAN MAARTEN WIT
}

\author{
Department of Paediatrics, Erasmus University Medical Centre/Sophia Children's Hospital, Rotterdam \\ [D.M.]; Leiden University Medical Centre [A.M.F., W.O., J.M.W.]; and Child Health Division, TNO \\ Prevention and Health [A.M.F., S.v.B., S.P.V.-V.], Leiden, The Netherlands
}

\begin{abstract}
We investigated pubertal development of 4019 boys and 3562 girls $>8$ y of age participating in a cross-sectional survey in The Netherlands and compared the results with those of two previous surveys. Reference curves for all pubertal stages were constructed. The 50th percentile of Tanner breast stage 2 was $10.7 \mathrm{y}$, and $50 \%$ of the boys had reached a testicular volume of $4 \mathrm{~mL}$ at $11.5 \mathrm{y}$ of age. Median age at menarche was $13.15 \mathrm{y}$. The median age at which the various stages of pubertal development were observed has stabilized since 1980. The increase of the age at stage G2 between 1965 and 1997 is probably owing to different interpretations of its definition. The current age limits for the definition of precocious are close to the third percentile of these references. A high agreement was found between the pubic hair stages and stages of pubertal (genital and breast) development, but slightly more in boys than in girls. Menarcheal age was dependent on height, weight, and body mass index. At a given
\end{abstract}

ABSTRACT

age tall or heavy girls have a higher probability of having menarche compared with short or thin girls. A body weight exceeding $60 \mathrm{~kg}(+1 \mathrm{SDS})$, or a body mass index of $>20(+1$ SDS), has no or little effect on the chance of having menarche, whereas for height such a ceiling effect was not observed. In conclusion, in The Netherlands the age at onset of puberty or menarche has stabilized since 1980 . Height, weight, and body mass index have a strong influence on the chance of menarche.

(Pediatr Res 50: 479-486, 2001)
BMI, body mass index
$\mathbf{P}_{\mathbf{5 0}}$, 50th percentile
$\mathbf{P}_{3}$, 3rd percentile
$\mathbf{P}_{\mathbf{9 7}}$, 97th percentile
SDS, SD score

\section{Abbreviations}


Table 1. Puberty sample: percentage of participating boys or girls per age group as percentage of the total age group included in the Dutch national survey*

\begin{tabular}{|c|c|c|c|c|c|c|}
\hline Age (y) & PH boys & G boys & TV boys & $\mathrm{PH}$ girls & B girls & Men \\
\hline $8-9$ & $49.1 \%$ & $49.1 \%$ & $42.7 \%$ & $60.2 \%$ & $61.1 \%$ & $59.3 \%$ \\
\hline $9-12$ & $73.2 \%$ & $72.9 \%$ & $66.5 \%$ & $78.1 \%$ & $80.5 \%$ & $85.6 \%$ \\
\hline $12-15$ & $54.4 \%$ & $54.3 \%$ & $51.3 \%$ & $57.4 \%$ & $58.5 \%$ & $76.9 \%$ \\
\hline $15-18$ & $49.9 \%$ & $49.9 \%$ & $47.6 \%$ & $51.1 \%$ & $52.1 \%$ & $74.8 \%$ \\
\hline $18-21$ & $42.5 \%$ & $42.4 \%$ & $40.4 \%$ & $33.6 \%$ & $33.9 \%$ & $83.8 \%$ \\
\hline
\end{tabular}

* 4019 boys and 3562 girls.

Abbreviations: PH, pubic hair; G, genital stage; TV, testicular volume; B, breast stage; Men, menarche.

height, weight, and pubertal development. In two earlier papers on the study performed in 1997, we concentrated on the secular trend of body stature, weight, and BMI and only briefly discussed pubertal development $(12,13)$. In the present paper we report on the reference data in more detail, as well as a comparison with the previous growth studies. Furthermore, we investigated the degree of concurrence of breast or genital stages with pubic hair stages and the relationship between the age at menarche and height, weight, and BMI.

\section{METHODS}

In a cross-sectional design the presence of secondary sexual characteristics was studied. All participants of the 1997 nationwide growth study aged $\geq 9$ y completed a questionnaire on demographic variables (3909 boys and 3454 girls). This sample can be regarded as representative of the general population. In a subgroup (puberty sample) we determined the stage of sexual maturation and age at menarche. The age distribution in the puberty sample showed an overrepresentation of children
$<15$ y of age (approximately 250 in each age group) compared with children $>15$ y (100-150 per age group; Table 1). Data were available from an additional group of 110 boys and 108 girls between 8 and $9 \mathrm{y}$ of age who had also completed the questionnaire. Pubertal data were available from approximately $50 \%$ of these children (Table 1). These observations were randomly distributed across the country.

In the analyses in this article age was used as a covariate, so this skewed age distribution will not affect the results. The composition of the puberty sample was comparable with the sample of a national survey with regard to region and level of education.

The measurements of height and weight were performed by trained staff. The pubertal stages were determined by visual inspection, using Tanner's criteria (14) as described in Table 2. In boys testicular volume was assessed using an orchidometer. To validate the accuracy of the measurement of testicular volume, the testicular volumes in 79 boys were measured by two observers. The Spearman correlation coefficient between the measurements of two observers was 0.82 ; the $95 \%$ confidence interval for the

Table 2. Definitions of Tanner stages

\begin{tabular}{|c|c|c|}
\hline Sex & Tanner stage & Description \\
\hline \multirow[t]{4}{*}{$\mathrm{F}$} & B1 & Preadolescent; elevation of papilla only \\
\hline & $\mathrm{B} 2$ & Breast bud stage; elevation of breast and papilla as a small mound, enlargement of areolar diameter \\
\hline & B3 & Further enlargement of breast and areola, with no separation of their contours \\
\hline & B5 & Mature stage; projection of papilla only, owing to recession of the areola to the general contour of the breast \\
\hline \multirow[t]{3}{*}{$\mathrm{F}$} & P1 & Preadolescent; no pubic hair \\
\hline & $\mathrm{P} 2$ & Sparse growth of long, slightly pigmented downy hair, straight or only slightly curled, appearing chiefly along the labia \\
\hline & P5 & $\begin{array}{l}\text { Adult in quantity and type, distributed as an inverse triangle of the classic feminine pattern. Spread to the medial } \\
\text { surface of the thighs, but not up the linea alba or elsewhere above the base of the inverse triangle }\end{array}$ \\
\hline \multirow[t]{3}{*}{ M } & G1 & Preadolescent; testes, scrotum, and penis are of about the same size and proportion as in early childhood \\
\hline & G2 & $\begin{array}{l}\text { The scrotum and testes have enlarged and there is a change in the texture of the scrotal skin. There is also some } \\
\text { reddening of the scrotal skin }\end{array}$ \\
\hline & G5 & Genitalia adult in size and shape. No further enlargement takes place after stage 5 is reached \\
\hline \multirow[t]{5}{*}{ M } & P1 & Preadolescent; no pubic hair \\
\hline & $\mathrm{P} 2$ & $\begin{array}{l}\text { Sparse growth of long, slightly pigmented downy hair, straight or only slightly curled, appearing chiefly at the base of } \\
\text { the penis }\end{array}$ \\
\hline & $\mathrm{P} 3$ & Considerably darker, coarser, and more curled; spreads sparsely over the junction of the pubes \\
\hline & P4 & $\begin{array}{l}\text { Hair is adult in type, but the area covered by it is still considerably smaller than in most adults. There is no spread to } \\
\text { the medial surface of the thighs }\end{array}$ \\
\hline & P5 & $\begin{array}{l}\text { Adult in quantity and type, distributed as an inverse triangle of the classical feminine pattern. Spread to the medial } \\
\text { surface of the thighs, but no up the linea alba or elsewhere above the base of the inverse triangle }\end{array}$ \\
\hline
\end{tabular}

Descriptions are taken from Marshall and Tanner $(2,3)$. Abbreviations: B, breast stage; P, pubic hair stage; G, genital stage. 

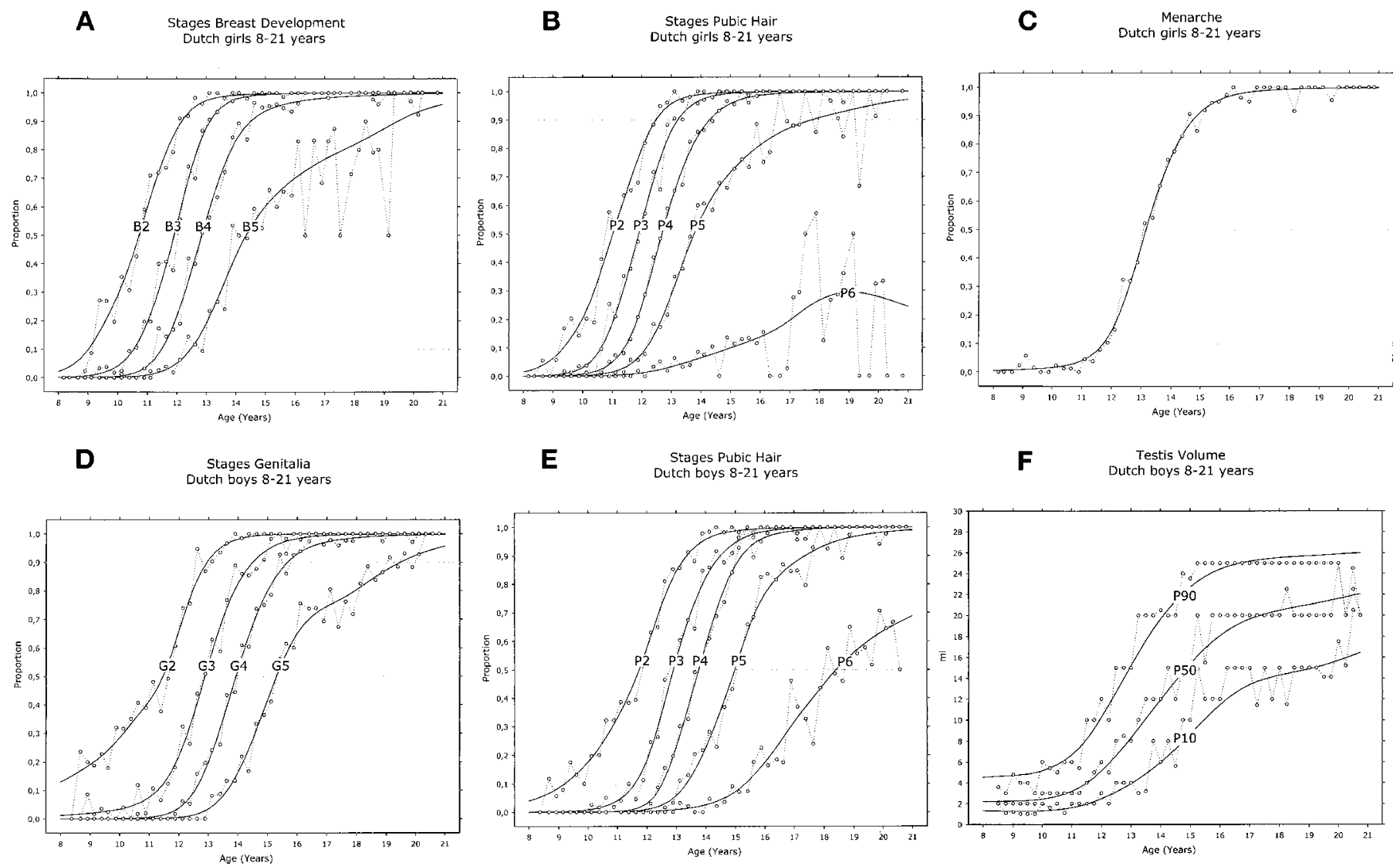

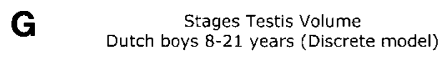

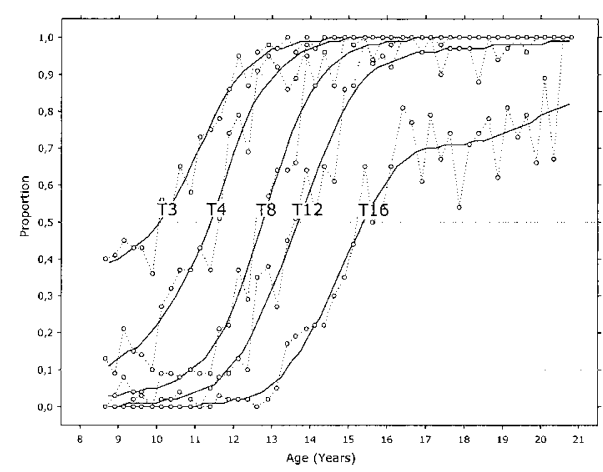

Figure 1. Reference curves for secondary sexual characteristics in The Netherlands, 1997. $A$, breast stage in girls; $B$, pubic hair stage in girls; $C$, menarche; $D$, genital stage in boys; $E$, pubic hair stage in boys; $F$, mean testicular volume; $G$, testicular volumes in early and midpuberty $(3,4,8,12$, and $16 \mathrm{~mL})$.

difference between observers appeared to be $0.4-2.0 \mathrm{~mL}(1.2 \pm$ $0.8 \mathrm{~mL}$ ). In midpuberty the interobserver differences were highest. Zachman et al. (15) reported a correlation coefficient of 0.83 and a mean difference in testicular volume between two observers of $2.9 \mathrm{~mL}$. The age at menarche was determined by the status quo method, asking a girl whether she had had her first period at the moment of the survey.

Demographic variables were assessed by a questionnaire. The highest level of completed education of the parents was used as a measure for socio-economic status. The country was divided in five geographical regions, one of them containing the four largest cities (12).

Statistical methods. For menarche and stages of secondary sexual characteristics, the reference curves were estimated by a generalized additive logistic model for each transition stage separately (16). This model describes the probability of each stage as a smooth function of age. The amount of smoothing was determined by cross-validation. LMS reference curves were derived for testicular volumes, in which the measured volumes were considered as a continuous measure (17).

To compare B or $\mathrm{G}$ stages and pubic hair stages in girls and boys, we calculated $\kappa$ as a measure of agreement (18).

\section{RESULTS}

Reference curves for pubertal stages and testicular volume. In Figure 1, $A-F$, we present the reference curves for sexual development. The dotted lines represent the crude data. The $\mathrm{P}_{50}$ 
ages can be read from the figures. The 10th and 90th percentile ages, which were published earlier as numerical data (12), can also be read from these graphics, being the ages at which the curves cross the 10th and 90th percentiles, respectively.

Figure 1 also shows the intervals between the consecutive pubertal stages, with a general pattern of a shorter interval between the third and fourth stage compared with the interval between stages 2 and 3. In Figure $1 G$, reference curves are presented for various testicular volumes.

The $\mathrm{P}_{3}$ values for $\mathrm{B} 2$ and $\mathrm{G} 2$ were 8.2 and 9.8 y respectively, and the $\mathrm{P}_{97}$ values were 12.7 and $13.4 \mathrm{y}$, respectively.

Comparison with the 1965 and 1980 growth studies. In Figure 2, we show comparisons between the timing of pubertal stages in the present study and the previous studies performed in 1965 and 1980. The $P_{50}$ values are shown for both boys and girls. For all stages a decreasing trend is seen between 1965 and 1980 with stabilization afterward. In contrast, G2 in boys increased from $11 \mathrm{y}$ in 1965 to $11.5 \mathrm{y}$ in 1997 , whereas the $\mathrm{P}_{50}$ of a testicular volume of $4 \mathrm{~mL}$ decreased from $12 \mathrm{y}$ in 1965 to $11.5 \mathrm{y}$ in 1997. In all studies the $\mathrm{SD}$ of the $\mathrm{P}_{50}$ ages is approximately $1 \mathrm{y}$.
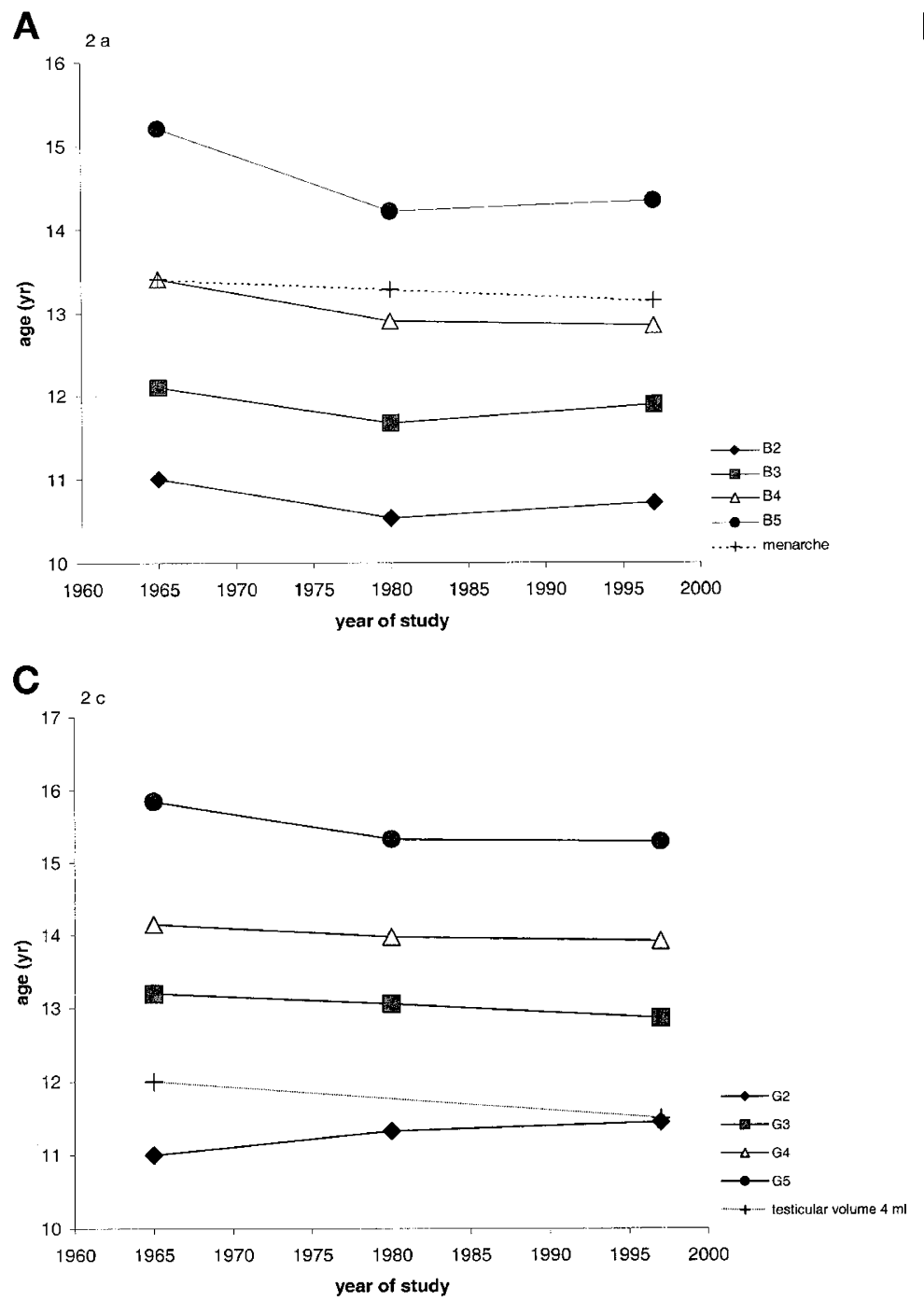

Relationship between pubertal stages. In Table 3 the relationships between the P stage and B or G stages are shown in absolute numbers. In girls in B1, 60 of 531 (11.3\%) showed pubic hair development, whereas $23.3 \%$ of girls in $\mathrm{P} 1$ showed breast development. In boys, G1 was accompanied by the presence of pubic hair in $10.2 \%$; boys in P1 had genital development in $24.9 \%$.

The agreement between $\mathrm{P}$ and $\mathrm{B}$ or $\mathrm{G}$ stage was expressed as $\kappa$ and Spearman correlation. The $\kappa$ values were 0.59 and 0.63 for girls and boys, respectively, indicating moderate to substantial agreement. The difference between the two $\kappa$ values was significant $(p<0.05)$. Spearman rank-order correlation was 0.91 both in boys and girls $(p<0.001)$.

Thus, in line with our hypothesis, in boys the gonadal and pubic hair development shows a closer mutual agreement than in girls, although the difference in $\kappa$ is only small.

Menarcheal age in relation to auxometric variables. In Figure 3 the probability of having menarche is depicted as function of age ( $x$ axis) and weight, weight SDS, height, height SDS, BMI, and BMI SDS (plotted on the $y$ axis).
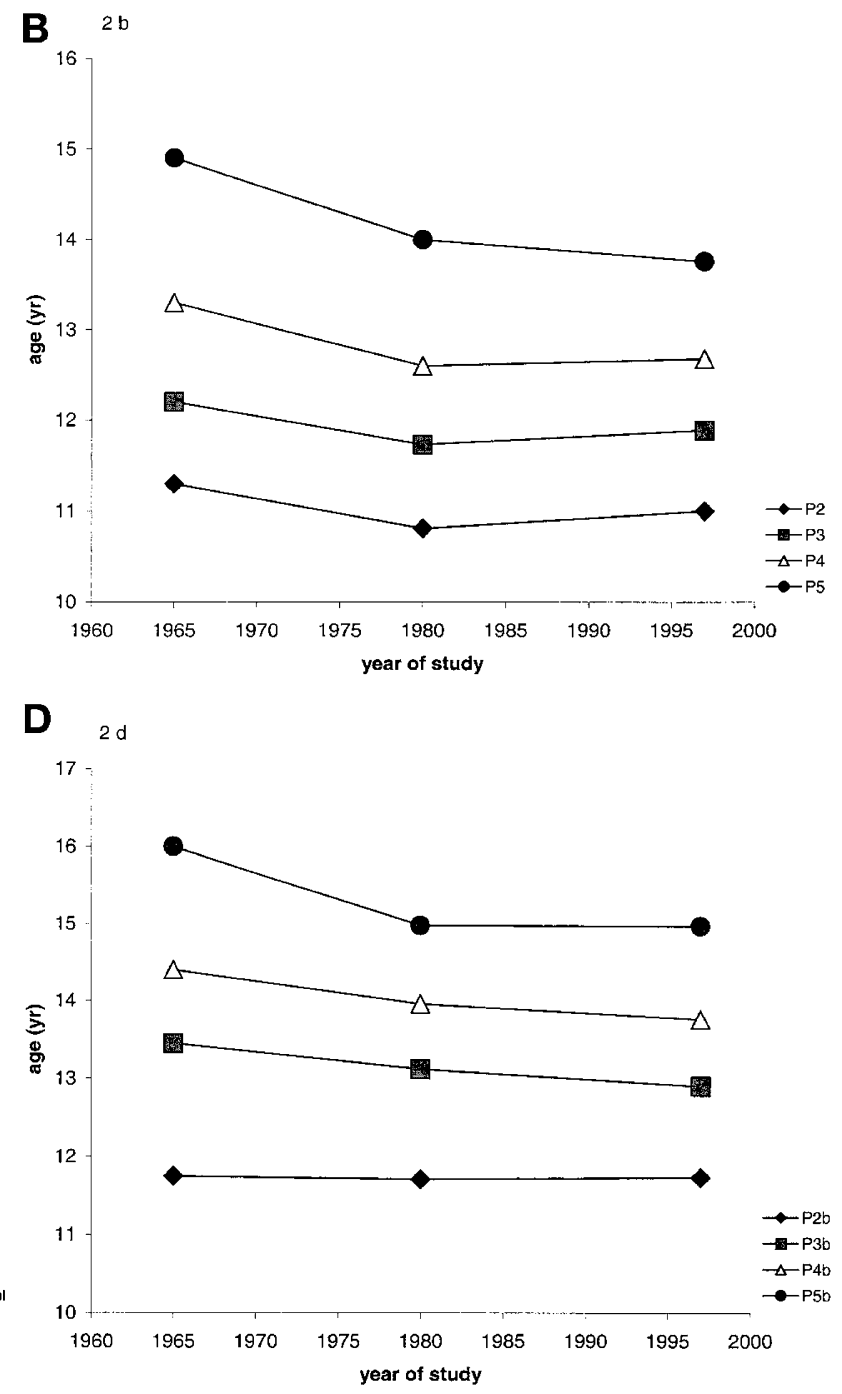

Figure 2. Sexual maturation in The Netherlands 1965-1997 [(1,11) and this study]; the $\mathrm{P}_{50}$ values of the different pubertal stages are given. $A$, breast stage and menarche; $B$, pubic hair stage in girls; $C$, genital stage in boys and testicular volume $4 \mathrm{~mL} ; D$, pubic hair stage in boys. 
Table 3. Distribution of $B$ and $P$ stages in girls and $G$ and $P$ stages in boys

\begin{tabular}{|c|c|c|c|c|c|c|}
\hline $\begin{array}{c}\text { Girls } \\
(n=2213)\end{array}$ & B1 & B2 & B3 & B4 & B5 & Total \\
\hline P1 & 471 & 124 & 19 & - & - & 614 \\
\hline P2 & 55 & 138 & 50 & 3 & 1 & 247 \\
\hline P4 & - & 4 & 58 & 186 & 71 & 319 \\
\hline P5 & - & - & 17 & 156 & 495 & 668 \\
\hline P6 & - & - & 5 & 23 & 122 & 150 \\
\hline $\begin{array}{c}\text { Boys } \\
(n=2360)\end{array}$ & G1 & G2 & G3 & G4 & G5 & Total \\
\hline P1 & 529 & 151 & 21 & 2 & $1 *$ & 704 \\
\hline P2 & 59 & 222 & 53 & 4 & - & 338 \\
\hline P3 & 1 & 47 & 124 & 20 & 1 & 193 \\
\hline
\end{tabular}

$\kappa=0.63(p<0.001) ; *$ this boy was $17.1 \mathrm{y}$ old, testicular volume, $20 \mathrm{~mL}$.

All figures show the expected increase in probability of menarche with increasing age and the additional effect of weight, height, and BMI (expressed as nominal values or as SDS).

They demonstrate that at a given age the heavier and taller girls have a higher probability of having menarche. However, the shape of the probability curves is different for the indices of weight (i.e. weight and BMI) in comparison to height. When weight or BMI exceeds a certain point, no or little further increase in probability is observed, as the curves have an almost vertical course from there. For weight this point is close to $62 \mathrm{~kg}$ (1 SDS), and for BMI it is approximately $20 \mathrm{~kg} / \mathrm{m}^{2}$ or 1 SDS. In the curve for weight expressed in kilograms, the vertical course is more obvious than in the curve for weight SDS.

In contrast, the figures on height show a continuing effect of height at a certain age. Some examples of the different ages at which there is $50 \%$ probability of having menarche with various SDS for weight, height, or BMI are shown in Table 4.

\section{DISCUSSION}

This study provides up-to-date references for pubertal stages in the Dutch population, which can be used for clinical purposes. In the interpretation of the reference curves for the consecutive pubertal stages, one should be aware, however, that our data are derived from a cross-sectional study. The reliability of the data is high, because of the relatively large numbers of subjects. On the other hand, no information is available about the tempo at which a child passes through the consecutive stages. Such information can only be obtained from a longitudinal study, such as the longitudinal assessment of puberty in boys and girls performed by Marshall and Tanner $(2,3)$. In general, reference centiles based on cross-sectional data have a larger variance than those based on longitudinal data. For pubertal development curves, this implies that the progression of stages for individuals is generally faster than the intervals between $\mathrm{P}_{50}$ stages obtained from cross-sectional references.

The second finding is that the positive secular change toward an earlier development of puberty between 1965 and 1980 has almost stabilized thereafter. During the whole period between 1965 and 1997, the $\mathrm{P}_{50}$ age of onset of puberty (stage B2) in girls decreased from $11.0 \mathrm{y}$ in 1965 to $10.7 \mathrm{y}$ in this study. The median age at menarche decreased by $0.25 \mathrm{y}$ in the same period, and by $0.5 \mathrm{y}$ from 1955 . In the last $17 \mathrm{y}$ only a small decrease of about $1.5 \mathrm{mo}$, from 13.28 to $13.15 \mathrm{y}$, was observed. A similar pattern of an apparent stabilization of a previously decreasing trend was observed in Oslo schoolgirls, in whom menarcheal age has reached a stable level for several decades (19). However, in Norway also the secular trend in body stature appears to have stopped (19). Maybe the stabilization reflects a situation in which the environmental conditions have allowed the child to reach the optimal genetic potential given the actual environmental conditions (4).

The only exception to this trend of a slow positive secular trend between 1965 and 1980 followed by near stabilization is the apparent increase of the median age at which boys reach $\mathrm{G} 2$ from $11.0 \mathrm{y}$ in 1965 to around $11.5 \mathrm{y}$ in 1997 . This finding contrasts with a decrease of the median age at attaining a testicular volume of $4 \mathrm{~mL}$ from $12.0 \mathrm{y}$ in 1965 to $11.5 \mathrm{y}$ in 1997. The most likely explanation of this discrepancy is that the interpretation of the definition of stage G2 must have been different in 1965 in comparison to $1980(1,20)$ and 1997.

In fact, the original definition of G2 as proposed by Marshall and Tanner (3) leaves much room for confusion, as it states that "[t]he scrotum and testes have enlarged and there is a change in the texture of the scrotal skin. There is also some reddening of the scrotal skin..." (see also Table 2). This description is not pertinent to the question of which of the three criteria mentioned is most relevant, and to whether all criteria have to be met or at least one or two of them. In addition, it does not strictly describe the minimum volume that the testis should 

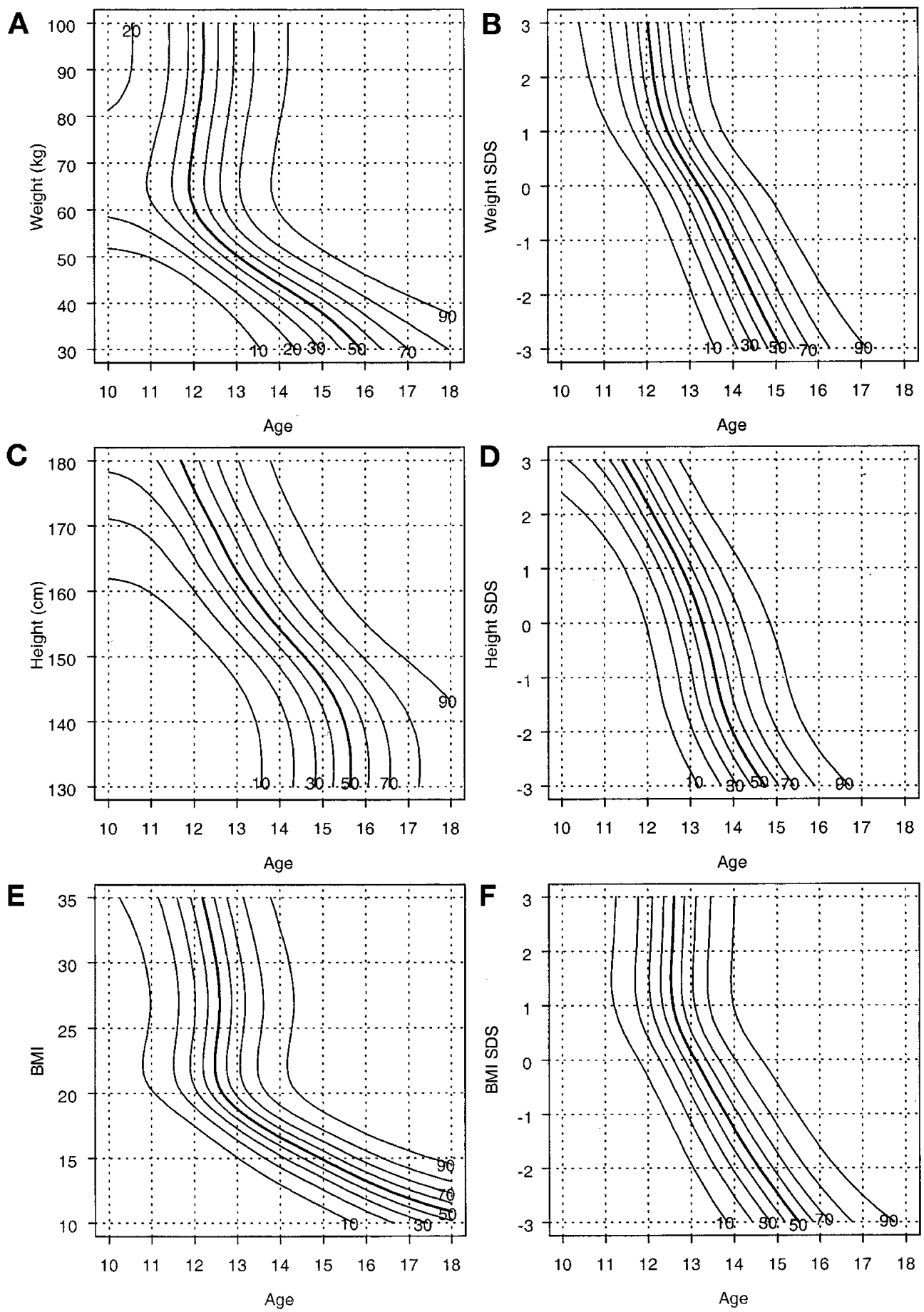

Figure 3. Probability of having menarche as a function of age and weight $(A)$, weight SDS $(B)$, height $(C)$, height SDS $(D)$, BMI $(E)$, and BMI SDS $(F)$. The probability is expressed as a percentage. A vertical course of the lines means that at a certain age the variable on the $y$ axis does not further contribute to increase the probability of having menarche. A transverse course implies additional effect of the variable on the $y$ axis on the probability of having menarche.

have before the genital stage may be labeled as G2. For example, there are good arguments that a testicular volume of $3 \mathrm{~mL}$ can already be considered as a sign of puberty $(15,21)$. In the present study the observers were taught to describe the genital stage as G2 if both enlargement of testicular volume and scrotum was observed and reddening of the scrotal skin was present. It appears likely that in 1965 the observers might have labeled the genital stage as G2 if at least one of the three criteria was present.
Based on these findings, but also on our experience in clinical trials (22), we believe that it is opportune to come to a redefinition of stage G2, to prevent more confusion in the future. We would prefer that the testicular volume, the criterion that is most easily measured, should be used as the only criterion. Furthermore, a volume of $3 \mathrm{~mL}$ appears a better indication of the onset of puberty than $4 \mathrm{~mL}(21,23)$.

Relatively few data are available on the accordance between $\mathrm{P}$ and $\mathrm{G}$ or $\mathrm{M}$ stages during puberty. Based on the theoretical 
Table 4. Influence of different SDS for weight, height, and BMI on the $P_{50}$ age of chance of menarche

\begin{tabular}{ccc}
\hline & SDS & Age $_{50}(\mathrm{y})^{*}$ \\
\hline \multirow{3}{*}{ Weight } & +2 & 12.1 \\
& +1 & 12.7 \\
& 0 & 13.2 \\
& -1 & 13.8 \\
Height & -2 & 14.5 \\
& +2 & 12.2 \\
& +1 & 12.8 \\
& 0 & 13.3 \\
\multirow{3}{*}{ BMI } & -1 & 13.7 \\
& -2 & 14.0 \\
& +2 & 12.7 \\
& +1 & 12.7 \\
& 0 & 13.1 \\
& -1 & 13.8 \\
& -2 & 14.7
\end{tabular}

* estimated from curves in Fig 3, $B, D$, and $F$.

view that, for girls, breast development is the initial event in pubertal development and testicular development for boys, these measures should be used as markers in clinical practice. In girls $\mathrm{P}$ stage is primarily a reflection of adrenal maturation, although the role of ovarian androgens is acknowledged in pubertal girls (24). In boys, $P$ stage is the reflection of a combined adrenal and testicular maturation, so that a higher agreement would be expected in boys than in girls. In fact, we found a higher agreement between P and G or B stage (expressed as $\kappa$ ) in boys than in girls, but both were significant. This suggests that pubertal development and pubic hair development frequently synchronize. With regard to the timing of both phenomena, we found that in general breast development starts somewhat earlier than pubic hair, in line with the findings of Marshall (2). However, pubic hair was seen before breast development in approximately one third of all girls in the English study (2), and in approximately $10 \%$ in our study. In stages B3 and G3 the distribution of P stages is equally divided and in the higher B or G stages the P scores tend to shift to the right, especially in boys, with higher $\mathrm{P}$ than $\mathrm{G}$ or M stage.

The definition of precocious puberty and delayed puberty should be based on the normal occurrence of secondary sexual characteristics in the population, but there is no consensus whether -2 SDS or -2.5 SDS should be used as a cutoff. We chose to use the usual cutoff measure of $-2 \mathrm{SD}$, which is close to the $\mathrm{P}_{3}$ and can be read from the reference curves in Figure 1.

The $\mathrm{P}_{3}$ age for $\mathrm{B} 2(8.2 \mathrm{y})$ is close to the age of $8.0 \mathrm{y}$, which is generally and internationally used as the age limit for the definition of precocious puberty, and we would therefore propose to continue using this figure. For boys the $\mathrm{P}_{3}$ of $\mathrm{G} 2$ stage is $9.8 \mathrm{y}$, whereas no reliable $\mathrm{P}_{3}$ data for testicular volume of 4 $\mathrm{mL}$ can be presented. Thus, the current cutoff ages for precocious puberty, i.e. $8 \mathrm{y}$ for girls and 9 y for boys, can be maintained in our country.

For delayed puberty, the $\mathrm{P}_{97}$ for $\mathrm{B} 2$ and $\mathrm{G} 2$ presented in "Results," as well as the $\mathrm{P}_{97}$ age for testicular volume of $4 \mathrm{~mL}$ $(13.8 \mathrm{y})$, point to a cutoff age for delayed puberty of $13 \mathrm{y}$ in girls and $14 \mathrm{y}$ in boys.
As mentioned before, in the United States a decrease in the age at onset of puberty in girls was observed (6). However, in that study the sample was not representative of the general population, as the girls were examined when they visited a general practitioner. The girls were heavier and taller than in the national American growth survey, and in $15 \%$ of the girls rated $\mathrm{B} 2$ by visual inspection no breast tissue was found at palpation (7).

We have shown that in addition to age, weight, height, and BMI influence the chance of having menarche in the age range $11-15 \mathrm{y}$ as well. Interestingly, the probability lines for weight and BMI show an almost vertical pattern in the range at which the SDS exceeds approximately 1 . Beyond such degree of (over)weight, weight or BMI hardly affects the probability of having menarche anymore. The cutoff level for BMI data are consistent with the results published in our earlier report, showing that premenarcheal girls in all age ranges had mean BMI $<20 \mathrm{~kg} / \mathrm{m}^{2}$ (13). Our data are in contrast to those of Marshall (25), who stated that the occurrence of menarche was not related to the attainment of a particular height, weight, or body composition, but mostly occurred after the peak of the adolescent growth spurt. However, the limited number of subjects in that study may have precluded the appearance of statistical significance in this respect. An interesting phenomenon is that height, in contrast to weight and BMI, exerts its influence on the probability of menarche over the full range.

It is generally assumed that the increase in socio-economic conditions and general health is the main contributing factor for the trend toward earlier maturation $(4,26,27)$. In most industrialized countries the increase in public health and socioeconomic conditions was accompanied by an increase in adult height and a decreasing age at attainment of pubertal events (28). The mechanisms through which these changes occur are unknown. On the physiologic substrate for earlier pubertal development, several hypotheses were discussed, for example, the so-called critical weight hypothesis $(8,29)$. Recent studies on leptin have suggested that this protein could act as a link between fat tissue and the central activation of the hypothalamus (30-32). Another line of research concerns the possible influences of estrogenlike substances in the environment on the timing of puberty, for example, phytoestrogens present in soy-based feeding (33). However, no human data are available that show an influence of infant feeding, containing phytoestrogens, on sexual maturation (34). The stabilization of the age at onset of puberty in a period when an increasing exposure to estrogenlike substances can be assumed argues against a causal link.

We conclude that the secular change toward earlier puberty has been stabilized in the last two decades in The Netherlands. No change in the definition of precocious puberty is warranted. The occurrence of menarche is not only dependent on age, but also on height, weight, and BMI. Beyond a weight or BMI of $+1.0 \mathrm{SDS}$, this dependency is less apparent. The agreement between the expression of gonadal maturation and pubic hair is slightly higher in boys than in girls.

Acknowledgment. The authors thank Inge Everhardus for studying the observer characteristics for testicular volumes. 


\section{REFERENCES}

1. Roede MJ, van Wieringen JC 1985 Growth diagrams 1980. Netherlands third nation-wide survey. Tijdschr Soc Gezondheidszorg 63(suppl.):11-32

2. Marshall WA, Tanner JM 1969 Variations in pattern of pubertal changes in girls Arch Dis Child 44:291-303

3. Marshall WA, Tanner JM 1970 Variations in the pattern of pubertal changes in boys. Arch Dis Child 45:13-23

4. Hauspie RC, Vercauteren M, Susanne C 1997 Secular changes in growth and maturation: an update. Acta Paediatr Suppl 423:20-27

5. Lindgren G 1996 Pubertal stages 1980 of Stockholm schoolchildren. Acta Paediatr 85:1365-1367

6. Herman-Giddens ME, Slora EJ, Wasserman RC, Bourdony CJ, Bhapkar MV, Koch GG, Hasemeier CM 1997 Secondary sexual characteristics and menses in young girls seen in office practice: a study from the pediatric research in office settings network. Pediatrics 99:505-512

7. Kaplowitz PB, Oberfield SE 1999 Reexamination of the age limit for defining when puberty is precocious in girls in the United States: implications for evaluation and treatment. Drug and Therapeutics and Executive Committees of the Lawson Wilkins Pediatric Endocrine Society. Pediatrics 104:936-941

8. Frisch RE, Revelle R 1970 Height and weight at menarche and a hypothesis of critical body weights and adolescent events. Science 169:397-399

9. Georgopoulos N, Markou K, Theodoropoulou A, Paraskevopoulou P, Varaki L, Kazantzi Z, Leglise M, Vagenakis AG 1999 Growth and pubertal development in elite female rhythmic gymnasts. J Clin Endocrinol Metab 84:4525-4530

10. de Wijn JF, de Haas JH 1960 Groeidiagrammen van 1-25 jarigen in Nederland [Growth diagrams for ages 1-25 years in The Netherlands]. Nederlands Instituut voor Praeventieve Geneeskunde, Leiden

11. van Wieringen JC, Wafelbakker F, Verbrugge HP, de Haas JH 1968 Groeidiagrammen 1965 Nederland [Growth diagrams 1965 The Netherlands]. Nederlands Instituut voor Praeventieve Geneeskunde TNO, Leiden

12. Fredriks AM, van Buuren S, Burgmeijer RJ, Meulmeester JF, Beuker RJ, Brugman E, Roede MJ, Verloove-Vanhorick SP, Wit JM 2000 Continuing positive secular growth change in The Netherlands 1955-1997. Pediatr Res 47:316-323

13. Fredriks AM, van Buuren S, Wit JM, Verloove-Vanhorick SP 2000 Body mass index measurements in 1996-7 compared with 1980. Arch Dis Child 82:107-112

14. Tanner JM 1969 Growth and endocrinology of the adolescent. In: Gardner L (ed) Endocrine and Genetic Diseases of Childhood. WB Saunders, Philadelphia

15. Zachmann M, Prader A, Kind HP, Hafliger H, Budliger H 1974 Testicular volume during adolescence. Cross-sectional and longitudinal studies. Helv Paediatr Acta 29:61-72
16. Hastie TJ, Tibshirani RJ 1990 General Additive Models. Chapman and Hall, London

17. Cole TJ, Green PJ 1992 Smoothing reference centile curves: the LMS method and penalized likelihood. Stat Med 11:1305-1319

18. Altman DG 1991 Practical Statistics for Medical Research. Chapman and Hall, London

19. Liestol K, Rosenberg M 1995 Height:weight and menarcheal age of schoolgirls in Oslo-an update. Ann Hum Biol 22:199-205

20. Taranger J, Engstrom I, Lichtenstein H, Svennberg-Redegren IVI 1976 Somatic pubertal development. Acta Paediatr Scand Suppl 258:121-135

21. Biro FM, Lucky AW, Huster GA, Morrison JA 1995 Pubertal staging in boys. J Pediatr 127:100-102

22. Rekers-Mombarg LTM, Kamp GA, Massa GG, Wit JM, Group DGHW 1999 Influence of growth hormone treatment on pubertal timing and pubertal growth in children with idiopathic short stature. J Ped Endocrinol Metab 12:611-622

23. Largo RH, Prader A 1983 Pubertal development in Swiss boys. Helv Paediatr Acta $38: 211-228$

24. Ankarberg C, Norjavaara E 1999 Diurnal rhythm of testosterone secretion before and throughout puberty in healthy girls: correlation with 17beta-estradiol and dehydroepiandrosterone sulfate. J Clin Endocrinol Metab 84:975-984

25. Marshall WA 1978 The relationship of puberty to other maturity indicators and body composition in man. J Reprod Fertil 52:437-443

26. Wyshak G, Frisch RE 1982 Evidence for a secular trend in age of menarche. N Engl J Med 306:1033-1035

27. Susanne C, Bodzsar EB 1998 Patterns of secular change of growth and development In: Bodzsar EB, Susanne C (ed) Secular Growth Changes in Europe. Eötvös University Press, Budapest, pp 5-27

28. Bodzsar EB, Susanne C 1998 Secular Growth Changes in Europe. Eötvös University Press, Budapest

29. Frisch RE 1987 Body fat, menarche, fitness and fertility. Hum Reprod 2:521-533

30. Flier JS 1998 What's in a name? In search of leptin's physiologic role. J Clin Endocrinol Metab 83:1407-1413

31. Kiess W, Reich A, Meyer K, Glasow A, Deutscher J, Klammt J, Yang Y, Muller G, Kratzsch J 1999 A role for leptin in sexual maturation and puberty? Horm Res 51(suppl S3):55-63

32. Clayton PE, Trueman JA 2000 Leptin and puberty. Arch Dis Child 83:1-4

33. Mazur W 1998 Phytoestrogen content in foods. Baillieres Clin Endocrinol Metab 12:729-742

34. Klein KO 1998 Isoflavones, soy-based infant formulas, and relevance to endocrine function. Nutr Rev 56:193-204 